\title{
The Modified Research of Paraffin Material for Machining
}

\author{
Jin $\mathrm{Hu}^{\mathrm{a}}$, Minghua Chen \\ Aviation Maintenance NCO Academy, Xinyang, 464000, China \\ abenchi9506@sina.com, bredit6@163.com
}

Keywords: paraffin wax system; stearic acid; toughening agent A; polyethylene; NC machining.

\begin{abstract}
The materials used in NC machine tools are usually steel, which is of high hardness. The influence factors for paraffin wax system performance are studied, which include the effects of stearic acid, toughening agent $A$, polyethylene and cooling-down methods. The material is prepared according to a certain proportion of the material by modification, which can be used in the mechanical processing of paraffin composite system to replace the material used in CNC processing. The practical application shows that the paraffin compound system can meet the requirements of NC machining and achieve the goal of energy saving and consumption, which is very effective.
\end{abstract}

\section{Introduction}

Machining of material is usually using rolled steel. Because of its high hardness and great intensity, beginners easily damage equipment and tools by wrong operation during the process of practice [1-2]. Especially in numerical control machine tools, it always causes large amount of waste materials or even causes some accidents due to programming error and tool error. From the material saving and safety point of view, the paraffin can be used as training materials instead of rolled steel [3]. There are many advantages using paraffin, such as low hardness, low cost, recyclable used repeatedly, and so on. So it does not need cutting fluid in machining process and does not damage the cutter. As a result, it can effectively avoid the misoperation which may bring personal injury and damage to the equipment. Simultaneously, it also has some shortcomings, such as high brittleness, not easy to clip, sticking to the knife, difficult to assembling and fixing due to its low impact toughness, low hardness and low intensity [4]. In order to improve the processing performance of paraffin wax, physical modification was studied by adding stearic acid, polyethylene and toughening agent.

\section{Test Part}

\subsection{The Test of Raw Materials.}

The test of raw materials are as follows: 54\# fully-refines paraffin wax is white translucent lump with the melting point of $54.1^{\circ} \mathrm{C}$ which is produced by Jingmen branch, China Petroleum Chemical Corporation; stearic acid is white round granules with the melting point of $56.1^{\circ} \mathrm{C}$ which is produced by Sichuan Tianyu Grease Chemical Co. Ltd; toughening agent A is yellow particles with the melting point of $62.1^{\circ} \mathrm{C}$ which is produced by Sichuan Tianyu Grease Chemical Co. Ltd; high density polyethylene is white particles which is produced by Qilu Chemical Co. Ltd; release agent is produced by Shanghai pharmaceutical Co. Ltd.

\subsection{Test Instruments.}

The test instruments are as follows: magnetic stirrer is produced by Shanghai Precision Science Instrument Co., Ltd; digital melting point instrument with WRS-1B is produced by Shanghai Precision Science Instrument Co., Ltd; petroleum wax penetration tester is produced by Shanghai Petroleum Instrument Factory; numerical control machine tool is produced by Jinan CNC machine tool factory. 


\subsection{Test Procedure.}

(1) Put the paraffin into $250 \mathrm{ml}$ beaker according to the proportion, then heat the paraffin wax to melt.

(2) Control the temperature at about $80^{\circ} \mathrm{C}$, weigh the stearic acid and toughening agent according to the proportion, add to the molten paraffin, then stir well.

(3) Heat to $120 \sim 140^{\circ} \mathrm{C}$, add a certain amount of polyethylene and release agent, keep stirring, then make them fully mixed.

(4) Pour into the mold, cool to room temperature, then obtain the experimental samples.

\subsection{Determination of Main Properties of Paraffin Composite System.}

The penetration is measured by the method of GB/T 4985 petroleum wax penetration which can characterize the hardness. The smaller the penetration, the greater the hardness. Evaluating its processing performance is through the NC machining for paraffin composite material.

\section{Results and Discussion}

\subsection{Effect of Stearic Acid on the Physical Properties of Paraffin Wax.}

The hardness and melting point of stearic acid is higher than paraffin, and it can be mixed with paraffin in any proportion. It is an excellent paraffin modifier [5][6]. Effect of stearic acid content on the physical properties of paraffin is shown in Table 1. From the table 1, it can be seen that hardness and melting point of paraffin increases with stearic acid content. When the mass fraction of stearic acid is in $20-80 \%$, the hardness of composite wax/stearic acid increases slowly because paraffin is still the main phases during this stage, and the system hardness is mainly determined by paraffin. When the mass fraction of stearic acid is in $80-140 \%$, the body of the paraffin/stearic acid system is stearic acid. The high hardness characteristics of stearic acid are fully reflected, because hardness of stearic acid is significantly higher than that of paraffin which makes the hardness of the system rising rapidly.

Table 1 Effect of stearic acid on physical properties of paraffin wax

\begin{tabular}{|c|c|c|c|c|c|c|}
\hline $\begin{array}{c}\text { Stearic acid content(relative } \\
\text { paraffin quality) }\end{array}$ & $0 \%$ & $20 \%$ & $60 \%$ & $80 \%$ & $100 \%$ & $140 \%$ \\
\hline Melting point & 54.0 & 54.2 & 54.6 & 55.2 & 55.9 & 56.1 \\
\hline Penetration $\left(25^{\circ} \mathrm{C}, 0.1 \mathrm{~mm}\right)$ & 15.6 & 15.1 & 13.8 & 13.1 & 10.2 & 6.5 \\
\hline Processing performance & poor & bad & common & good & good & $\begin{array}{c}\text { commo } \\
\mathrm{n}\end{array}$ \\
\hline
\end{tabular}

In the process of numerical control machining of paraffin wax/stearic acid system, it is found that the processing performance is better than that of pure paraffin, but it is still relatively soft when the content of stearic acid is low. On the one hand, the hardness and strength of the paraffin wax increase which the processing performance becomes better with the increase of stearic acid content; on the other hand, the toughness and plasticity gradually decline, the hardness is too high which makes the processing performance worse. The blank pieces begin to appear during the processing and the tool is easily worn out, especially when the content of stearic acid is more than $140 \%$. Therefore, the optimum content of stearic acid is $100 \%$.

\subsection{Effect of Toughening Agent A on the Physical Properties of Paraffin Wax/Stearic Acid System.}

Because stearic acid reduces the toughness of wax, it can be modified by adding toughening agent in paraffin/stearic acid system in order to improve the processing performance further. The toughening agent $\mathrm{A}$ is a mixture of many ingredients which cost is higher than that of paraffin wax. It contains a large amount of $\mathrm{C}_{15} \mathrm{H}_{31} \mathrm{COOC}_{30} \mathrm{H}_{61}$ and $\mathrm{C}_{25} \mathrm{H}_{51} \mathrm{COOC}_{26} \mathrm{H}_{53}$, which has good toughness and miscibility with paraffin wax. Table 2 shows the effect of toughening agent on the 
physical properties of paraffin wax/stearic acid system. It is shown in Table 2 that with the increase of toughening agent A content, the melting point of the composite system increases slightly, while the hardness decreases gradually. This may be due to the high melting point and toughness of the toughening agent compared with the paraffin/ stearic acid system. In the process of machining, the mixed system has good impact toughness and is difficult to break. The cutting performance is better, but continuous chip is formed in cutting. When the content of the toughening agent is higher than $15 \%$, the hardness decreases a lot which affects the processing performance. Therefore, the optimum content of the toughening agent $\mathrm{A}$ is $10 \%$ considering the cost and processing.

Table 2 Effect of toughening agent A on physical properties of paraffin/stearic acid composite system

\begin{tabular}{|c|c|c|c|c|c|c|}
\hline $\begin{array}{c}\text { toughening agent A } \\
\text { content(relative paraffin } \\
\text { quality) }\end{array}$ & $0 \%$ & $2 \%$ & $5 \%$ & $10 \%$ & $15 \%$ & $20 \%$ \\
\hline Melting point & 55.9 & 56.4 & 56.8 & 57.3 & 57.5 & 58.2 \\
\hline Penetration( $\left.25^{\circ} \mathrm{C}, 0.1 \mathrm{~mm}\right)$ & 10.2 & 10.3 & 10.8 & 11.2 & 12.7 & 13.3 \\
\hline Processing performance & good & good & good & $\begin{array}{c}\text { mediu } \\
\mathrm{m}\end{array}$ & good & good \\
\hline
\end{tabular}

\subsection{Effect of Polyethylene on Physical Properties of Paraffin Wax/Stearic Acid/Toughening Agent A System.}

Polyethylene is a kind of straight chain polymer synthesized from ethylene monomer [7]. It has large molecular weight, high strength and melting point, which can be dissolved in liquid paraffin wax at $120-140^{\circ} \mathrm{C}$ comparing with paraffin wax. Paraffin wax system can significantly improve the melting point, hardness, gloss, sealing strength and high temperature cohesiveness after adding polyethylene. At the same time, the crystallization of paraffin wax is formed, thus it improves the performance of paraffin wax. In order to obtain a paraffin compound system with high melting point and high strength, polyethylene can be added into paraffin/stearic acid/toughening agent A system. Table 3 shows the influence of polyethylene on the physical properties of paraffin/stearic acid/toughening agent A system. It is shown as Table 3, the melting point of the composite system increases significantly, and the hardness also increases obviously with the increase of polyethylene content. However, the toughness of the composite system will decrease obviously when the content of polyethylene is more than $10 \%$. Moreover, the concentration of polyethylene in the paraffin solution is too high, and it is easy to gather together, which easily affects the dispersion of the system and reduces the mechanical properties of the system. All this reduces the processing performance. As a result, the optimum dosage of polyethylene is $10 \%$. Under this condition, the melting point of the paraffin compound system is $70.3^{\circ} \mathrm{C}$, and the hardness is moderate, which is very suitable for mechanical processing.

Table 3 Effect of polyethylene on physical properties of paraffin/stearic acid/toughening agent A composite system

\begin{tabular}{|c|c|c|c|c|c|c|}
\hline $\begin{array}{c}\text { Polyethylene content(relative } \\
\text { paraffin quality) }\end{array}$ & $0 \%$ & $2 \%$ & $5 \%$ & $10 \%$ & $15 \%$ & $20 \%$ \\
\hline Melting point & 57.3 & 64.5 & 68.4 & 70.3 & 78.8 & 85.6 \\
\hline Penetration $\left(25^{\circ} \mathrm{C}, 0.1 \mathrm{~mm}\right)$ & 11.2 & 10.9 & 9.3 & 7.8 & 6.9 & 6.1 \\
\hline
\end{tabular}

\subsection{Effect of Cooling Methods on Process Ability of Composite System.}

When the liquid paraffin is formed, its cooling speed will change the crystal structure of paraffin wax. The faster the cooling speed, the finer thee crystal formation of paraffin wax, the higher the mechanical strength, the better the cutting performance. But for the paraffin wax composite system, commonly used cooling way can use water cooling, nature cooling, slow cooling (oven cooling) etc. In this case, if the water cooling is adopted, it can cause rapid shrinkage of the system surface due 
to the rapid cooling speed, and the temperature difference between inside and outside is large, resulting in a large amount of shrinkage control, and even generating cracks. In the experiments, the paraffin wax composite system is put into the baking oven with $60-70^{\circ} \mathrm{C}$. As the oven cools to room temperature, the paraffin wax composite system is found without shrinkage and cracks, which indicates that slow cooling is the best way to cool the paraffin wax composite system.

\section{Application}

In the process of mechanical processing of students on our college, the above paraffin wax compound system was applied to the numerical control, and it was found that it can fully meet the demand of practical teaching and training of computer numerical control milling machine tools. It is not only very safe but also easy to recycle and reuse. It can significantly reduce the production and teaching costs. The practice effect is very good. Therefore, it has good popularizing value.

\section{Conclusion}

(1) Stearic acid can improve the melting point and hardness of wax, and stearic acid is $100 \%$ (relative to paraffin quality), and the process ability of the system is better.

(2) The toughening agent A can improve the toughness and melting point of the wax/stearic acid composite system, and the toughening agent is $10 \%$ (relatively paraffin mass), and the process ability of the system is better.

(3) Polyethylene can improve the melting point and hardness of wax/stearic acid/toughening agent A composite system, polyethylene is $10 \%$ (relatively paraffin quality), and the process ability of the system is better.

(4) The best formula of paraffin compound system for NC machining is: paraffin wax: stearic acid: polyethylene: toughening agent $A=1: 1: 0.1: 0.1$ (mass ratio), and adopts slow cooling mode.

(5) The wax compound system can meet the requirements of NC machining, and it is safe and economical. It has important significance for ensuring the qualified rate of NC machining products.

\section{References}

[1] Zhou Haiying. Study on the paraffin products for practical teaching of CNC machining. Manufacturing Technology \& Machine Tool [J], 2008, 10:20-21.

[2] Yan Yuye. Influence of the physics in paraffin wax by the additive [J]. Contemporary Chemical Industry, 2007, 36(3):246-249.

[3] Bezchlebova J. Effects of short-chain chlorinated paraffins on soil organisms [J]. Ecotoxicology and Environmental Safety, 2006(9):70-76.

[4] Zhang Jiaojiao, Zhao Tianbo, Chai Yuqiao, Wang Lili. Preparation and characterization of high content paraffin wax microcapsules and micro/nanocapsules with poly methyl methacrylate shell by suspension-like polymerization [J]. Chinese Journal of Chemistry, 2017, 35(4):497-506.

[5] Feng Yi. The application of composite paraffin material in numerical control machining. Machinist Metal Cutting [J], 2009, 29(17):29-30.

[6] Yuan Fang, Zhang Yi, Xi Yuzhen, Zhou Kai, Wang Chengyu. Preparation of Paraffin Emulsion and Its Application in Wood Processing [J]. Guangdong Chemical Industry, 2017, 44(12):1-3.

[7] Eto S, Noda H, Noda A. Chiral separation of barbiturates and hydantoins by reversed-phase high-performance liquid chromatography using a 25 or $50 \mathrm{~mm}$ short ODS cartridge column via $\beta$-cyclodextrin inclusion complexes [J]. Journal of Chromatography B: Biomedical Sciences and Applications, 1992, 579(2):253-258. 